\title{
¿Es el episcopado un sacramento distinto del presbiterado?
}

\author{
Puntos de vista de Juan Lorenzo Berti
}

Los amplios comentarios ${ }^{1}$ dedicados al n. 21 de la constitución dogmática "Lumen gentium" del Vaticano II, en el que se propone la doctrina sobre la sacramentalidad del episcopado, han vuelto a poner sobre el tapete el tema que sirve de epígrafe a estas páginas, después del compás de espera marcado por los debates conciliares, con la consiguiente expectación de los teólogos ${ }^{2}$. Terminado el Concilio, y partiendo de los datos por él aportados, la discusión ha vuelto a salir a la calle. El episcopado es un sacramento, sí; pero, ¿hasta qué punto es distinto del presbiterado? ¿Cuál es la naturaleza de esa distinción? ¿Qué significa, en la mente del Concilio, "la plenitud del sacramento del Orden" ${ }^{3}$ que se confiere con la consagración episcopal? ¿Qué alcance tiene la afirma-

1 Prácticamente en todos los comentarios que se han dedicado a la Constitución "De Ecclesia" hay algún trabajo sobre la sacramentalidad. Véanse en particular, B. MoNSEGU, Comentarios a la Constitución sobre la Iglesia: Sacramentalidad del Episcopado, ed. BAC., Madrid 1966, 403-427, donde se citan otros trabajos; D. B. DupuY, "Bulletin d'histoire des doctrines la theologie de l'episcopat": Revue des Sciences Phil. et Theol. 49 (1955) 288-342; NICOLAU, "Episcopado en la Constitución "Lumen Gentium": Salmanticensis 12 (1965) 451-507; C. Pozo, "La teología del episcopado en el cap. III de la Const. De Ecclesia": Estudios eclesiásticos 40 (1965) 39-162; U. LATTANZI, "De nexu agnoscendo inter episcopalem consecrationem et sacra Ecclesiae munera": Divinitas 9 (1965) 392-415. Se podría aumentar la lista, pero no lo creemos necesario.

2 Antes del Concilio el tema había sido ampliamente debatido. La bibliografía es abundantísima: J. CoNGAR, "Faits, problemes et reflexions a propos du pouvoir et des rapports entre le presbyterat et l'episcopat": La Maison-Dieu 19 (1948) 10-128; LECUYER, La grace de la consecration episcopal": Revue des Sciences Phil. et Theol. 36 (1952) 389-417; B. MoNSEGU, "El constitutivo formal del episcopado": XXII Semana Española de Teología, Madrid 1963, 65-84; Bou. LARAND, "La concecration episcopal est-elle sacramentelle": Bull. Lit. Eccl. 54 (1953) 3-36; M. LóPEZ MARTf́NEZ, "La distinción entre obispos y presbíteros": XXII Semana Española de Teología, Madrid 1963, 85-156.

Para una bibliografía más amplia sobre el tema, véase U. DoMíNGUEz DEL VAL, "La eclesiología en los últimos años (1950-1964). Orientaciones bibliográficas": Salmanticensis 12 (1965) 319-394; SERENTHA, "Ressegna bibliografica sull'episcopato": Scuola Cattolica 181 (1963) 343-271.

${ }^{3}$ Const. Lumen gentium, n, 21, 1, ${ }^{2}$ ed. BAC., Madrid 1966, 43. 
ción conciliar de que "con la imposición de las manos y las palabras consecratorias se confiere la gracia del Espíritu Santo y se imprime el sagrado carácter" "4, referida a la ordenación de un nuevo obispo? ¿En qué relación están la gracia y el carácter del episcopado con los del presbiterado? Estas y otras preguntas vuelven a encontrar eco en libros y revistas de teología, de biblia, de historia, de liturgia, etc., aportando cada especialista sus razones. En realidad, todas estas disciplinas están implicadas a la hora de dar una solución al problema.

El Concilio, por su parte, no ha hecho más que canalizar la corriente doctrinal, cada día más numerosa, que, a partir del Tridentino, venía corriendo en sentido positivo hacia la sacramentalidad del episcopado, pero sin determinarse por una explicación concreta de este hecho ${ }^{5}$, dejando a la libre discusión de los teólogos sus puntos menos claros y, en particular, sus relaciones con el presbiterado. $\mathrm{Ni}$ siquiera ha querido definir "solemnemente" 6 la misma sacramentalidad, no obstante haberla puesto como fundamento de la magnífica construcción teológico-pastoral que, en torno al episcopado, se ha levantado en el capítulo tercero de la constitución "de Ecclesia".

Estando así las cosas, hemos creído oportuno, con motivo del centenario de Berti, traer a colación sus puntos de vista sobre el particular. Nos ha parecido la suya una buena aportación que, incluso después del Concilio, tiene valor positivo. Primero, porque nos da una visión estupenda del panorama doctrinal de su época sobre el tema, panorama que, prácticamente, ha cambiado bien poco con el pasar de los años. Y, segundo, porque la doctrina que propone está, a nuestro entender, dentro de las insinuaciones que el mismo Vaticano II sugiere para una solución definitiva.

Berti dedica al episcopado como sacramento el capítulo IX de su libro "De Ordine" ". Un capítulo que apenas cuenta cuatro páginas,

4 Ibid. 44 .

5 Conf. Relatio super caput III textus emendati schematis Const. de Ecclesia a Card. Köning, 7.

6 Ibid. 6.

7 El título general de la obra de Berti es De theologicis Disciplinis. Hemos empleado para nuestro estudio la edición de Venecia 1742. El capítulo 9 "De Ordine" corresponde al tomo octavo de la obra, pp. 78-81, según la antedicha edición. A estas páginas nos referimos siempre al citar dentro del texto o en nota. 
pero cuya riqueza de contenido es digna de amplio comentario. Es el suyo un estudio denso y bien pensado, escaso en literatura pero abundante en erudición teológica, en el que se demuestra una vez más agudo pensador y digno representante de la Escuela Agustiniana.

Comienza su exposición con una referencia completa de los diversos sentidos nominales de la palabra griega "Episcopos", a la que corresponde "episcopus" en latín, poniendo de relieve las significaciones a que han dado lugar: superinspector, speculator, superspectator, visitator, etc., y conviniendo con San Agustín ${ }^{8}$ en que "Episcopatus nomen est oneris non honoris. Graecum est enim, atque inde ductum vocabulum, quod ille qui praeficitur, eis quibus praeficitur superintendit, curam eorum scilicet gerens".

Pasa revista, asimismo, a los lugares del Antiguo y del Nuevo Testamento en los que aparece expresamente citada (Esdras, 11, 22; Salm. 108; I Petri, 2, 25) haciendo ver que su significación real corresponde exactamente al doble sentido nominal de prefectura y de servicio, por lo que concluye:

"Iure igitur meritoque, ii, qui in Ecclesiastica Hierarchia ceteris praeponuntur, insigniti sunt honestissimo amplissimoque nomine episcoporum". (p. 78).

En apretado resumen expone, a continuación, las tres sentencias que sus contemporáneos y anteriores han defendido sobre la sacramentalidad o menos del episcopado. Es interesante dejar constancia de ellas porque, en realidad, son las que han prevalecido a través de dos siglos, limitándose los teólogos posteriores, e incluso los de nuestros días, a tomar posiciones de una $\mathrm{u}$ otra parte y repitiendo, con escasas innovaciones, las razones ya dadas.

1. ${ }^{\text {a }}$ SENTENCia: El episcopado es orden en sentido amplio, pero no sacramento.

8 De Civ. Dei, XIX, 19, CSEL. 40/2, 404. Hay varios estudios sobre el episcopado como servicio en San Agustín: M. JourJon, L'Eveque et le peuple de Dieu selon saint Augustin. Etude de théologie pastorale. (These de doctorat, Lyon). Ronéot. année 1948-1949; ID., L'éveque et le peuple de Dieu selon saint Augustin en "Saint Augustin parmi nous", Le Puy-París 1954, 149-178; J. MoRÁN, "La presenza di S. Agostino nel Concilio Vaticano II": Augustinianum 6 (1966) 460-488. 
Piensan así -dice Berti- Hugo de San Víctor 9 , Pedro Lombardo ${ }^{10}$, Santo Tomás ${ }^{11}$, San Buenaventura ${ }^{12}$ y otros muchos ${ }^{13}$.

El nombre de orden - explican - puede tomarse en un doble sentido. Uno más amplio, en cuanto es una potestad espiritual no sólo de jurisdioción, sino también para poner ciertas acciones sagradas, como consagrar el crisma, ungir las frentes de los bautizados, iniciar a los ministros de la Iglesia, etc.... Así considerado, el episcopado es orden.

Sin embargo, en sentido estricto, es decir, en cuanto que el orden es un sacramento instituído por Cristo para consagrar y ofrecer la Eucaristía y confiere la potestad y el carácter necesarios para desempeñar tal oficio, el episcopado no es orden ni puede serlo, porque no es dable concebir potestad más amplia y sublime que la de consagrar y ofrecer el cuerpo de Cristo (p. 78).

Es ésta, en definitiva, una visión del orden en dos dimensiones separadas 0 , al menos, separables: como una potestad sobre el cuerpo físico de Cristo --en este sentido y sólo en él se puede hablar de orden-sacramento-y como una potestad espiritual sobre el cuerpo místico de Cristo, en cuyo caso el orden no es propiamente sacramento ${ }^{14}$.

Berti no comparte esta opinión. Su visión del orden es unitaria. De tal forma que toda la potestad episcopal, en cuanto episcopal, tiene raíz sacramentaria (p. 80). No se trata solamente de una falta de jurisdicción en el presbítero, por vía de no concesión de facultades para poner ciertas acciones sagradas (confirmar, ordenar, etc.), o de una ampliación de jurisdicción en el obispo que le capacite para ponerlas, quedando en pie la igualdad en ambos del sacramento del orden (Ib.). El episcopado es un grado sacramental y sacerdotal, superior en orden y jurisdicción al presbiterado.

Por otra parte, no se puede admitir, en línea de principio, que el

9 De Sacramentis, 1. 2, p. 3, c. 3, PL. 176, 423.

10 Sent., 1. 4, d. 24, n. 11, PL. 192, 904.

11 In IV Sent., d. 24, q. 3, a. 2; Suppl., q. 37, a. 2; q. 40, a. 4.

12 In IV Sent., d. 24, p. 2, a. 2, q. 3.

13 Veáse C. Pozo, "Tres posibles concepciones del sacramento del orden: a propósito de la sacramentalidad del episcopado: Revista española de teología 24 (1964) 131-132. En este trabajo se citan bastantes autores, antiguos y modernos, que defienden esta tesis.

14 Esta doctrina, aplicada por Santo Tomás al episcopado, le lleva a negar la sacramentalidad del mismo. He aquí sus palabras: "Ordo potest accipi dupliciter. Uno modo secundum quod est sacramentum. Et sic... ordinatur omnis ordo ad Eucharistiae sacramentum. Unde cum episcopus non habeat potestatem superiorem sacerdoti quantum ad hoc, episcopatus non erit ordo". (Suppl., q. 40, a. 5). 
episcopado no diga referencia a la Eucaristía. Es cierto que no confiere la potestad de consagrar y ofrecer el cuerpo de Cristo - potestad que Berti supone necesariamente en el que va a ser consagrado obispo, por ser ya presbítero- ${ }^{15}$, pero no es menos cierto que por la consagración episcopal se confiere la potestad de consagrar, mediante la ordenación, a los ministros de la Eucaristía. Su relación a la Eucaristía es indirecta, pero real. En el plan de la economía sacramentaria la potestad de consagrar el cuerpo de Cristo y la de preparar a la misma consagración, mediante la ordenación de nuevos ministros, se suponen mutuamente. Sin obispos que ordenen - viene a decir Berti- no hay presbíteros que consagren. Sin obispos, por tanto, no hay Eucaristía.

2. ${ }^{a}$ senTENCIA : El episcopado es orden y sacramento, pero no distinto del presbiterado.

Defienden esta tesis Paludano ${ }^{16}$, Vázquez ${ }^{17}$, Gamaqueo ${ }^{18}$ y otros ${ }^{19}$. Entre los agustinos Gavardi ${ }^{20}$, Tomás de Estrasburgo ${ }^{21}$ y Gibbon ${ }^{22}$.

$\mathrm{Su}$ posición doctrinal puede resumirse en estos términos: En la consagración episcopal no se imprime un nuevo carácter, distinto del carácter sacerdotal del presbiterado, pero en virtud de ella el carácter sacerdotal preexistente se graba más hondamente, se perfecciona y se amplía a nuevos oficios, de la misma manera que por la segunda imposición de las manos en la ordenación presbiteral el carácter sacerdotal, ya existente en virtud de la primera, se amplía y se extiende a la potestad de perdonar los pecados ${ }^{23}$. El episcopado es, por tanto, orden y sacramento, pero "ab ordine sacerdotali non distinguitur nisi prout

15 La potestad episcopal, según Berti, "ex divina institutione solis sacerdotibus communicatur" (De Ordine, c. 9).

16 In IV Sent., d. 24 , q. 7 , a. 4.

17 Disp. 240, c. 5.

18 De sacris Ordinat., c. 9

19) Cfr. nota 13.

20 Theologia exantiquata juxta orthodoxam Beatissimi Ecclesiae Magistri Augustini doctrinam..., Romae 1646, VI, 520-525.

21 In IV Sent., d. 24, a. 2.

22 Theologia scholastica ad mentem D. Thomae, VII, Maguntiae 1669, in 4. Vid. H. HuRTER, Nomenclator Literarius, IV, Oenipotente 1910, 30-31; T. LóPEz, Monastici Augustiniani Continuatio, II, Valladolid 1903, 499; J. F. OSSINGER, Bibliotheca Augustiniana, Ingolstadii 1768; ristampa anastatica, Torino 1963, 206.

23 De esta opinión es, particularmente, Vázquez, cfr. nota 17, quien llega a admitir dos ordenaciones diferentes en la consagración presbiteral, correspondientes a la primera imposición de las manos por la que se confiere la potestad de consagrar el cuerpo de Cristo y a la segunda, después de la comunión, por la que se confiere la potestad de perdonar los pecados. 
perficiens secernitur a perfectibili, sit in exemplo intensior qualitas, aut scientiae habitus de una ad aliam ratiocinationem procedens" (p. 78).

Según esta teoría, no sólo no se puede hablar de una independencia del episcopado, como sacramento, en relación al presbiterado. Ni siquiera es admisible su mutua distinción. Se trata sólo de una perfección del carácter sacerdotal del presbítero, en el sentido de que es ampliado jurisdiccionalmente a nuevos oficios. Son elocuentes, a este respecto, los ejemplos propuestos por los defensores de la tesis. Paludano habla del hábito de la ciencia que pasa de un raciocinio a otro ${ }^{24}$. Gamaqueo, de una nueva relación, como cuando el rey encarga a uno otro oficio distinto ${ }^{25}$. Gavardi pone de relieve la identidad de ambos caracteres teniendo ante los ojos la imagen del niño que se hace hombre ${ }^{26}$.

Berti tampoco está de acuerdo con esta sentencia. El episcopado, como demostrará más tarde, es un grado sacerdotal, distinto del presbiterado, al que corresponde por tanto carácter distinto. No se trata sólo de la ampliación de un carácter preexistente, sino de la impresión de un nuevo carácter. Cuál sea la distinción entre ambos, lo veremos más adelante. Baste ahora con decir que, según Berti, hay que hablar de una distinción "connotativa" (p. 80).

3. ${ }^{a}$ SENTENCIA: El episcopado es sacramento completamente (omnino) distinto del presbiterado.

Berti suma su nombre al de los defensores de esta tesis, entre los cuales cita a Juan Mayor, Scoto, Cayetano, Pedro Soto, San Belarmino ${ }^{27}$,

24 In IV Sent., d. 24, q. 7, a. 4.

25 De Sacris Ordinat., c. 9.

26 Gavardi expresa claramente su teoría en el siguiente párrafo: "Homo parvus ex eo quod fit magnus, non fit aliter numero realiter distinctus; sed solum acquirit perfectionem, magnitudinem et plenitudinem hominis, ut est per se notum; sed sacerdotium magnum et parvum se habent sicut homo magnus et parvus; sicut enim parvus convenit in hoc cum homine magno quod potest convertere cibum in propriam substantiam, differt tamen quia homo parvus nequit generare alterum hominem defectu perfectionis et magnitudinis ad generandum exactae; ita sacerdos parvus convenit in hoc cum sacerdote magno quod potest convertere panem et vinum in corpus et sanginem Christi, differt tamen quia sacerdos nequit generare alium sacerdotem, quem potest generare sacerdos magnus; et hoc quia illi deficit perfectio, magnitudo et plenitudo sacerdocii ad efficiendos alios sacerdotes exactae; ergo sacerdotium magnum et parvum non distinguuntur realiter in eodem subjecto, sed tantum per modum perficientis et perfectibilis, completi et incompleti seu magnificantis et magnificati" (GAVARDr, o. c. 524).

27 De Controversiis, III, Napoli 1858, 767. En este mismo lugar San Belarmino anota las citas correspondientes a Juan Mayor, Scoto, Cayetano, Pedro Soto, etc... 
Estio ${ }^{28}$ "et canonistae fere omnes", por lo que hace a sus antecesores, y a Haberto ${ }^{29}$, Juenin ${ }^{30}$, Witasse, Le-Droint, Piette, entre sus contemporáneos, pasando, en seguida, a exponer su modo de pensar y las pruebas del mismo.

\section{SACRAMENTALIDAD DEL EPISCOPADO.}

La proposición con que encabeza el ilustre agustino la parte probatoria no puede ser ni más interesante ni más clara para valorar el alcance de su doctrina: "Ordo Episcopatus est sacramentum, et quidem a presbyteratu distinctus" (p. 78). Sacramentalidad, pues, y distinción. Dos cuestiones que, en su sentir, están íntimamente unidas, no obstante las dificultades que plantean los defensores de la segunda sentencia.

Desdoblada así la tesis, nuestro autor desdobla también las pruebas de la misma, poniendo en claro en la primera parte las razones de la sacramentalidad y, en la segunda, las de la distinción.

\section{El episcopado es sacramento.}

Nos hallamos ante la formulación de una verdad indiscutible para Berti, cuyas pruebas localiza en la Sagrada Escritura, en el Magisterio y en la Tradición.

a) La prueba escriturística va montada sobre el siguiente argumento: Por los textos de San Pablo (I Tim. 4, 14 y I Tim 1, 6-7) consta que Timoteo fue ordenado per impositionem manuum presbyterii y que tal ordenación le confirió la gracia, razones estas por las que los textos citados son usados por los Santos Padres y por el Tridentino ${ }^{31}$ para probar la sacramentalidad del orden en general. Ahora bien, San Pablo

28 Estio, Guillermo. 1542-1613. Holandés. Profesor y rector de la Universidad de Duoai. Destacó como teólogo y escriturista. Escribió: In IV Sent.; Orationes theologicae: Adnotationes in praecipua ac difficiliora S. Scripturae loca, etc.... Cfr. DTC. V/1, 871-878.

29. De Ord., c. 6. HABERT, Luis. 1635-1718. Francés. Gran teólogo, aunque tachado de jansenista. Escribió varias obras entre las que destaca: Theologia dogmatica et moralis ad usum Seminarii Catalaunensis. Cfr. DTC. VI/2, 2.0142.015 .

30 Comentarius historicus et dogmaticus de Sacramentis, disert. 9, c. 2. JuENIN, Gaspar. 1650-1713. Teólogo del Oratorio. Además de la obra ya citada, escribió Institutiones Theologiae ad usum seminariorum, libro tachado de jansenismo; Compendium theologiae, etc. Cfr. DTC. VIII/1, 1.719-1.721.

31 D. 959 . 
habla, en concreto, de la ordenación episcopal de Timoteo, según se desprende de los mismos textos y como confirman los santos Padres ${ }^{32}$, Santo Tomás y otros intérpretes. Luego, o el episcopado es orden o el orden no es sacramento (ib.).

Si hay alguna orden - afirma Berti- de la que conste con seguridad su sacramentalidad, según la Sagrada Escritura, esa es precisamente el episcopado, puesto que a ella se refiere San Pablo en los textos que se aducen para probar la sacramentalidad del orden. Si, pues, admitimos que el orden es sacramento, fundándonos en los textos citados, debemos admitir lógicamente, en virtud de los mismos textos, que el episcopado lo es en primer lugar. De lo contrario habría que concluir que el orden no es sacramento ${ }^{33}$, "quod nefas est affirmare" (p. 78).

La prueba de Berti está en plena línea conciliar. El Vaticano II, aunque sin formularlo, usa del mismo argumento. En el n. 21 de la constitución dogmática "de Ecclesia", al dar los textos escriturísticos en que se funda la sacramentalidad del episcopado, cita expresamente las palabras de San Pablo, valorándolas a la luz del Tridentino, al que cita en nota. El Tridentino les daba fuerza probativa general de la sacramentalidad del orden; el Vaticano II concretiza su valor probatorio al episcopado, cuando dice:

"Para realizar estos oficios tan altos, fueron los apóstoles enriquecidos por Cristo con la efusión especial del Espíritu Santo (cfr. Act. 1, 8; 2. 4; Io. 20, 22-23), y ellos, a su vez, por la imposición de las manos, transmitieron a sus colaboradores el don del Espíritu (cfr. I Tim. 4, 14; 2 Tim. 1, 6-7), que ha llegado hasta nosotros en la consagración episcopal" 34.

b) En conexión con el argumento escriturístico Berti encuentra una nueva prueba de la sacramentalidad del episcopado en el Concilio Tridentino, coordinando inteligentemente dos textos conciliares: He aquí sus palabras:

"Hinc deducitur probatio altera ex Tridentino Concilio, cuius laudato capite tertio haec sunt verba: Cum Scripturae testimonio, Apostolica

32 Berti cita, entre otros, a San Juan Crisóstomo, Teofilacto, Ecumenio. No hemos podido controlar los lugares exactos, a falta de indicación por parte de Berti.

33 San Belarmino es de la misma opinión. Comentando los textos de San Pablo, a los que venimos refiriéndonos, dice, a modo de conclusión: "Quare si ordinatio episcopalis non est sacramentum, non possumus ex Scripturis aperte probare ordinationem esse sacramentum" (Ibid., cfr. nota 27).

34 Lumen Gentium, n. 21, 1. ${ }^{\mathrm{a}}$ ed. BAC., 43. 
traditione et Patrum unanimi consensu perspicuum sit, per Sacram Ordinationem, quae verbis et signis exterioribus perficitur, gratiam conferri, dubitare nemo debet Ordinem esse vere et proprie unum ex septem sanctae Ecclesiae sacramentis: inquit enim Apostolus, Admoneo te, ut resuscites gratiam Dei, quae est in te per impositionem manuum mearum. Non enim dedit nobis spiritum timoris sed virtutis et dilectionis et sobrietatis. Eadem sacrosancta Synodus proximo capite docet sacra Ordinatione Episcoporum, sacerdotum et ceterorum ordinum constitui Ecclesiasticam Hierarchiam, quam divina ordinatione institutam definit sexto eiusdem sessionis canone. Oecumenica ergo Synodus agnoscit in episcopatu impositionem manuum, quae est sacrae Ordinationis materia, divinam institutionem, ordinationem sacram, supernam gratiam, spiritumque virtutis atque Hierarchiae principatum" (p. 78-79).

El texto ha sido largo pero interesante. Sus implicaciones pueden ser varias según el punto de mira que se tome. Nosotros creemos descubrir el hilo conductor sobre el que avanza la argumentación de Berti en dos conceptos fundamentales y correlativos: Jerarquía sagrada y sagrada Ordenación. El segundo de ellos, según el Tridentino, es causa y fundamento del primero. $\mathrm{Si}$, pues, en la Jerarquía hay grados distintos por divina institución y la puerta de entrada en la misma es la Ordenación sagrada, síguese que habrá tantas ordenaciones sacramentales distintas, cuantos son los grados distintos de esta Jerarquía.

El sacramento del orden es el sacramento constitutivo de la Jerarquía y ésta es, por tanto, sacramental. "Nemo $\longrightarrow$ dice Berti- perfecta ratione in Hierarchia constituitur nisi per sacramentum sacrae ordinationis; quare electus sed nondum consecratus episcopus, non habet potestatem aliquam exercendi ea que sunt ordinis" (p. 79). Y, poco más adelante, añade a modo de conclusión: "Cum ergo potestas Ecclesiasticae Hierarchiae conferatur sacra ordinatione... negari non potest Episcopum ad supremum ac ab aliis distinctum Hierarchiae gradum per sacramentum ordinationis ascendere" ${ }^{35}$.

Por otra parte, el Tridentino, en el sentir de Berti, supone en la consagración episcopal todas las condiciones del verdadero sacramento. Es un signo sensible, que confiere la gracia, como atestiguan las palabras de San Pablo. Es, además, de institución divina, puesto que por ella llegan los obispos al primer grado de la Jerarquía, la cual es de origen divino.

35 Sería interesante hacer un estudio comparando esta doctrina de Berti con la del Vaticano II. Constatamos solamente, que también el Vaticano II ha puesto de relieve este aspecto de la Jerarquía como algo sacramental. (Cfr. Lumen gentium, n. 21 y 22). 
"¿Quid vero neccesarium ulterius est ut episcopi inauguratio ad sacramenti dignitatem evehatur?" (ibid.).

c) Por lo que hace al argumento de tradición Berti constata, uno tras otro, los siguientes datos, a los que concede solamente carácter confirmativo, debido a la oscuridad de los testimonios, en muchos casos, y a su incertidumbre en otros:

1. Todos los santos Padres distinguen perfectamente y citan por separado el episcopado, presbiterado y diaconado, como tres órdenes jerárquicas distintas, atribuyendo a cada una potestad y oficios diferentes.

2. No faltan Santos Padres que, hablando de la consagración episcopal, la califican expresamente de sacramento ${ }^{36}$.

3. En los documentos pontificios y en las colecciones canónicas se hace clara distinción entre el "electus" y el "episcopus" 37.

4. Desde el principio de la literatura eclesiástica la ordenación episcopal, de la misma manera que las demás órdenes sagradas, recibe el nombre de "Jeirotonia", entre los griegos, y de "ordo" y "manus impositio" entre los latinos ${ }^{38}$.

5. Cuando los escritores eclesiásticos enumeran las diversas órdenes citan siempre al episcopado, unos en el séptimo, otros en el octavo lugar; particularmente los griegos ${ }^{39}$.

d) Finalmente propone Berti una prueba de razón, haciendo ver cómo en la consagración episcopal se dan todos los elementos constitutivos del verdadero sacramento de la Nueva Ley (p. 81).

1. Es, ciertamente, un signo sensible, ya que se confiere mediante la imposición de las manos del consagrante, dentro de una ceremonia sagrada y con rito más solemne, sin duda, que las demás ordenaciones.

2. Que confiera la gracia, lo demuestran abiertamente las palabras,

36 Entre otros, San León Magno, Serm. 2, c. 1-2, PL. 54, 142-144.

37 "Constat ex capitulo Transmissam... quinimo ex cap. Tua nuper... in quibusvis Romanorum Pontificum Epistolis... in Canonum Collectionibus" (p. 79).

38 "... prout evidens est ex Occidentalis et Orientalis Ecclesiae libros omnibus Eucologicis, ex IV Canone magnae Nicenae Synodi, ex Codice Canonum Ecclesiae Romanae edito a Quesnello num. 6, ex Antiochenis 17, 18, 19; ex praecitatis Tridentini verbis, ex Epist. Inocentii I ad Victricium, et Gelasii ad Episcopos Lucaniae, atque ex monumentis alii plusquam mile" (p. 79). Cfr. L. SALTET, Les Réordinations. Etude sur le Sacrament de l'Ordre, 2." ed., París 1907.

${ }_{39}$ Así "Patres Cartaginensis Concilii IV, Auctor opusculi de septem Ecclesiae gradibus in Appendice Op. Hieronymi, Rabanus Maurus in I libro de Clericorum institutione, Simeon Thessalonicensis de Sacris Ordinat. cap. 6, aliique Latini; Graecique unanimiter" (p. 79). 
tantas veces citadas, de San Pablo a Timoteo, en las cuales es de notar cómo la colación de la gracia se hace depender de un signo sensible, cual es la imposición de las manos. Se trata, por tanto, de una gracia conferida "ex opere operato". Gracia que es, además, sacramental, como admite el mismo Tridentino ${ }^{40}$.

3. El hecho de que la Iglesia reconozca como válidas las ordenaciones conferidas por obispos cismáticos, e incluso herejes, argumenta a favor del carácter episcopal. En este punto Berti cita repetidamente a San Agustín, en su controversia con los donatistas ${ }^{41}$. Los obispos han recibido en su ordenación el sagrado carácter de éste, de tal forma está impreso en su alma que ni la misma herejía puede hacerlo desaparecer. Se trata de una potestad indeleble. "Quid est autem potestas indelebilis, nisi aut character, aut characteris effectus? (Ib.).

Confirma también la existencia del carácter episcopal la razón "vulgar y trillada" de que una vez conferido debidamente el episcopado no puede ser reiterado por nueva consagración.

4. En cuanto a la institución divina del sacramento del episcopado, el testimonio de la Escritura es claro. Consta evidentemente que los Apóstoles fueron obispos. "Illos vero quisnam tali dignitate exornavit nisi sacramentorum auctor et Ecclesiae institutor?" (Ib.). Por eso se dice en los Hechos de los Apóstoles, 20, 28, que los obispos fueron puestos por el Espíritu Santo para regir la Iglesia de Dios.

"Omnia ergo - termina Berti- ad sacramentum Ordinis necessaria in Episcopatu adinveniuntur, nomen, institutio, materia, forma, gratia, character" (pp. 79-80).

El episcopado, por tanto, es sacramento.

$40 \quad$ D. 959.

41 Contra Felicem, 1. I, c. 12, CSEL. 25/2, 813; Contra epist. Parmeniani, 1. II, c. 13 , CSEL. 51, 79. Varios autores se han preocupado del tema: A. M. RoGUET, "La théologie du caractere et l'incorporation a l'Eglise": La Maison-Dieu 32 (1952) 74-89. Dedicada a San Agustín desde la página 79 a la 89 ; J. R. N. NoLAN, The doctrine of $S$. Augustine on the sacramental character. Disertatio ad Lauream, Facultas Theologica Pontificii Athenaei Lateranensis, 1956. (Dactilografiada); N. M. HaRING, "St. Augustine's use of the word Character": Medieval Studies 14 (1952) 79-97. 
II. El EPISCOPADO ES SACRAMENTO DISTINTO DEL PRESBITERADO.

Para probar la segunda parte de su tesis, Berti recopila en un argumento conclusivo los apuntados anteriormente en favor de la sacramentalidad :

"Iamvero, si episcopatus Ordo et Sacramentum sit, prout existimamus, cum peculiari ritu, distincta consecratione, diversa ceremonia, propriisque materia et forma perficitur, conferatque ulterius potestatem ordinandi, chrisma conficiendi et consignandi, quam vi Ordinis non habet presbyter; certa illatione consequitur, quod episcopatus sit sacramentum a presbyteratu distinctum: quod erat propositionis pars altera" (p. 80).

No contento, sin embargo, con esta formulación tan categórica, establece a renglón seguido, una comparación entre el episcopado y el presbiterado, principalmente por lo que hace a la gracia y al carácter que uno y otro confieren, para determinar el alcance de esta distinción.

La comparación se instituye entre el episcopado y el presbiterado como sacramentos contradistintos. Es decir, el episcopado se considera no como un todo completo, resultante de una doble ordenación - presbiteral y episcopal - y, por ende, compuesto de dos caracteres diversos para Berti, como queda apuntado ${ }^{42}$, el presbiterado pertenece a la esencia del episcopado, de tal forma que es inconcebible un obispo que no sea presbítero-, sino en cuanto sacramento que confiere una gracia y un carácter peculiares y, por tanto, preterpresbiterales.

¿Qué distinción existe, pues, entre la gracia y el carácter que se confieren por la consagración episcopal y los conferidos por la consagración presbiteral?

Al plantearse esta pregunta Berti tiene presente la opinión de cuantos, acostumbrados a ver en la filosofía la panacea universal ${ }^{43}$, exigen una distinción "entitativa" de los efectos sacramentales para poder hablar de sacramentos diversos. No hace falta, dice Berti, tal distinción: "mea quidem sententia sufficit si gratia et character connotative tantum diversa sint ut de gratia et charactere Confirmationis scripsi" (p. 80).

Qué entienda Berti por distinción connotativa lo dice claramente,

42 Cfr. nota 15.

43. "Est - dice Berti- quaestio nata inter scholasticos illi physiologiae, quae entitatum fecundissima parens est, assuetos" (p. 80). 
refiriéndose a la gracia, en su tratado sobre la Confirmación ${ }^{44}$. "Connotative" se opone a "entitative" y significa "ratione effectuum". Y explica: No se puede hablar de gracias sacramentales distintas "entitative" porque la gracia santificante no es ninguna "entitas" 45 , y otra cosa no hace la gracia sacramental sino añadir a la gracia santificante "aliquid effectivum specialis effectuls ad quod ordinatur sacramentum" "46. O, como dice San Buenaventura, "in sacramentali gratia et est gratia gratum faciens, et effectus specialis quem habet virtute sacramenti: et in quantum gratum faciens una est, sed ratione effectuum distinguuntur" ${ }^{47}$. $\mathrm{Si}$, pues, la única distinción posible entre la gracia sacramental y la santificante es "ratione effectuum" o "connotativa", síguese que entre dos gracias sacramentales diferentes no puede haber más distinción que esta connotativa, puesto que ambas, en cuanto "gratum faciens" se identifican con la misma gracia santificante y sólo se distinguen de ella "ratione effectuum". En aquello que no es común pueden distinguirse. En lo que es común han de convenir necesariamente.

Aplicando esta doctrina general a nuestro caso, creemos interpretar la mente de Berti si decimos que la gracia sacramental del episcopado se distingue de la gracia sacramental del presbiterado porque la primera se ordena a la digna administración del orden y de la confirmación, mientras la segunda se ordena a la digna confección y administración de la Eucaristía.

Interpretando asimismo el sentir de Berti, a la luz de su doctrina sobre la distinción que media entre las gracias sacramentales del bautismo y de la confirmación, creemos poder afirmar que la gracia sacramental del episcopado no es "absolute loquendo" más perfecta que la gracia del presbiterado, ya que es mayor, en sí, la potestad de consagrar el cuerpo de Cristo que la de ordenar y confirmar. Pero sí lo es "comparative" en cuanto que, supuesta la gracia del presbiterado, es mejor si el sacerdote puede trasmitir a otros el poder de consagrar el cuerpo de Cristo, por medio de la ordenación, que si tiene sólo el poder de consagrar la Eucaristía. A tal potestad "comparative" mayor, corresponde también una gracia "comparative" mayor.

44 De Confirmatione, c. 9 , thesis $3 .^{a}$

45 "Sententia nostra gratia sanctificans est quidem inhaerens qualitas et superaddita animae habitudo, sed non entitas recondita inter Aristotelicas categorias" (Ibid.).

46 La frase es de Santo Tomás. Vid. Summa Theol:, p. 3, q. 72, art. 7, ad 3.

47 In IV Sent., D. 7, a. 2, q. 2, 
Por lo que se refiere al carácter, Berti aplica los mismos principios que llevamos enunciados. No se puede hablar, por tanto, de caracteres "entitative" diversos, sino sólo "connotative", en cuanto que el del episcopado faculta para ordenar y confirmar, mientras el del presbiterado faculta sólo para consagrar y ofrecer la Eucaristía.

Como conclusión de su trabajo, nuestro autor, sale al paso de posibles objeciones. Destacamos dos entre ellas, cuya solución ayudará a esclarecer su pensamiento.

1. Si el episcopado es orden y sacramento, síguese que las órdenes no son siete sino ocho. A lo que contesta:

"Respondeo in hoc argumento dirimendo parum sudandum esse: siquidem Episcopatus ac presbyteratus sub uno sacerdotii ordine comprehenduntur, sive sacerdotium in duos Ordines dispertitur, in unum quo traditur spiritualis potestas Eucharistiam offerendi et, in excellentiorem alium, quo ulterius confertur auctoritas illos qui Eucharistiam conficiunt et inmolant ordinandi et consecrandi" (p. 81).

Por esta razón los Padres hablan de sacerdocio de primero y de segundo orden ${ }^{48}$. Y el Tridentino ${ }^{49}$, al enumerar las siete órdenes, no llama a la primera "la de los presbíteros" sino "la de los sacerdotes".

2. Es tal la naturaleza de las órdenes sagradas que, en caso de que se confiera una, pasando por alto otra inferior, la orden conferida imprime carácter y no puede ser reiterada. Sin embargo está mandado que nadie sea ordenado obispo que no sea sacerdote.

"Ideo - contesta- non posse aliquem in episcopum ordinari nisi presbyteratu sit initiatus, quoniam potestas episcopi ad consecrandum, consignandum et ordines conferendos, cum eximia sit et praestantissima, ex divina institutione solis sacerdotibus communicatur" (p. 81).

Estas palabras de Berti vienen a confirmar una vez más cuanto había dicho anteriormente, de acuerdo con San Belarmino, cuyas son estas

48 Vid. L'Épiscopat et L'Eglise universelle. Ouvrage publié sous la direction de Y. Congar et B,-D, DUPUY, París 1962.

49. D. 958, 
palabras: "Non enim potest intelligi episcopus, qui non sit sacerdos, cum nihil sit aliud episcopus, nisi summus seu primus sacerdos" ${ }^{50}$.

Aquí mismo ponemos punto final a nuestro estudio.

Como se habrá podido observar, estábamos en lo cierto cuando afirmábamos, al principio de este trabajo, que los puntos de vista de Berti sobre la sacramentalidad del episcopado tienen valor positivo, incluso después del Concilio.

P. Pedro Rubio, O. S. A.

50 De controversiis, III, Neapoli 1858,768 . 